\title{
Predictors of recovery from post-traumatic stress disorder after the dongting lake flood in China: a 13-14 year follow-up study
}

Wenjie Dai ${ }^{1}$, Jieru Wang ${ }^{1,2}$, Atipatsa C. Kaminga ${ }^{1,3}$, Long Chen ${ }^{1,4}$, Hongzhuan Tan $^{1}$, Zhiwei Lai ${ }^{5}$, Jing Deng ${ }^{1}$ and Aizhong Liu $^{1 *}$

\begin{abstract}
Background: Floods are some of the most common and destructive natural disasters in the world, potentially leading to both physical injuries and psychological disorders, including post-traumatic stress disorder (PTSD). PTSD can damage functional capacity and interfere with social functioning. However, little is known about recovery from PTSD after floods. This study used 2013-2014 follow-up data on survivors of the 1998 Dongting Lake flood who were diagnosed with PTSD in 2000 to measure the prevalence rate of PTSD at follow-up and identify predictors of recovery from the PTSD diagnosis in 2000.

Methods: Participants included survivors who had been diagnosed as having PTSD in 2000 after the 1998 Dongting Lake flood. PTSD at follow-up was reassessed using the PTSD Checklist-Civilian version. Information on demographics, trauma-related stressors, post-trauma stressors, social support, and coping style were collected through face-to-face interviews. The association between the independent variables and PTSD at follow-up was analyzed using logistic regression analyses.

Results: A total of 201 participants with a PTSD diagnosis in 2000 were included in this study. A total of $19.4 \%$ of the flood survivors with PTSD in 2000 continued to suffer from PTSD in 2013-2014. In the multivariable logistic regression model, individuals who had lost relatives $(\mathrm{OR}=12.37,95 \% \mathrm{Cl}=2.46-62.16)$, suffered from bodily injury $(\mathrm{OR}=5.01,95 \% \mathrm{Cl}=1.92-13.08)$, had a low level of social support $(\mathrm{OR}=5.47,95 \% \mathrm{Cl}=1.07-27.80)$, or had a negative coping style (OR $=4.92,95 \% \mathrm{Cl}=1.89-12.81)$ were less likely to recover from PTSD.

Conclusions: The prevalence rate of PTSD at follow-up indicates that natural disasters such as floods may have a negative influence on survivors' mental health for an extended period of time. Individuals who have lost relatives, suffered from bodily injury, had a low level of social support, or had a negative coping style were less likely to recover from PTSD. Therefore, effective psychological intervention measures are necessary for facilitating the recovery process from PTSD, especially for individuals with adverse prognostic factors.
\end{abstract}

Keywords: Post-traumatic stress disorder, Predictors, Recovery, Flood

\footnotetext{
* Correspondence: lazroy@live.cn

${ }^{1}$ Department of Epidemiology and Health Statistics, Xiangya School of Public

Health, Central South University, Hunan, China

Full list of author information is available at the end of the article
}

(c) The Author(s). 2016 Open Access This article is distributed under the terms of the Creative Commons Attribution 4.0 International License (http://creativecommons.org/licenses/by/4.0/), which permits unrestricted use, distribution, and reproduction in any medium, provided you give appropriate credit to the original author(s) and the source, provide a link to the Creative Commons license, and indicate if changes were made. The Creative Commons Public Domain Dedication waiver (http://creativecommons.org/publicdomain/zero/1.0/) applies to the data made available in this article, unless otherwise stated. 


\section{Background}

Post-traumatic stress disorder (PTSD) is a psychological disorder caused by unusual threats or catastrophic events. According to the Fifth Edition of the Diagnostic and Statistical Manual of Mental Disorders (DSM-5), PTSD consists of four clusters of symptoms, namely, intrusion, avoidance, negative alterations in cognition and mood, and hyper-arousal [1]. PTSD can damage functional capacity and interfere with social functioning [2]. Hidalgo's study showed that the lifetime prevalence of PTSD in the general population was approximately 1 to 9 \% [3]. More generally, individuals with PTSD may experience a long recovery process after traumatic events [4]. For example, James found that half of the police officers with PTSD after the September 11, 2001 terrorist attacks - with a diagnosis made between 2003 and 2007 continued to have PTSD in 2011-2012 [5]. Additionally, according to a Chinese study, one-third of convalescent severe acute respiratory syndrome (SARS) patients with PTSD in 2003 were reported to have PTSD after the 4year follow-up [6]. However, different traumatic events may result in different PTSD rates and different PTSD prognoses. Currently, research on PTSD has mainly focused on the incidence of PTSD or the risk factors of chronic PTSD after traumatic events such as earthquakes [7] and wars [8]. Studies on PTSD experienced after floods, let alone addressing the predictive factors of PTSD recovery after floods, are limited [9].

Floods are some of the most common and destructive natural disasters in the world, potentially leading to direct economic loss, death and psychological injuries, particularly in developing countries with limited coping mechanisms [10]. China has been seriously affected by floods. According to statistics, a flood in Sichuan in 2011 caused 31 deaths and 160 injuries [11]. Moreover, in 2010, a flood in Jilin damaged 301,000 houses, and a total of 118,000 houses collapsed [12]. The most devastating flood struck Dongting Lake in Hunan, China in 1998. This flood left hundreds of thousands of residents homeless and damaged many infrastructural and agricultural projects, leaving some survivors with psychological problems, including PTSD.

An epidemiological survey was conducted after the Dongting Lake flood between January and May 2000, revealing that the prevalence of PTSD among adult survivors was $9.2 \%[13,14]$, and the onset of PTSD after the flood was significantly associated with age, gender, education, flood experience, and social support $[13,15]$. However, the prognosis of those individuals with PTSD was unknown. Therefore, the aim of our study was to investigate PTSD recovery progress and to identify likely predictive factors of PTSD recovery among Dongting Lake flood survivors who were diagnosed with PTSD in 2000.

\section{Methods}

\section{Participants}

Prior to this follow-up study, a cross-sectional study was conducted between January and May 2000, almost 2 years after the Dongting Lake flood. The study covered eight counties (Datonghu, Yueyang, Qianlianghu, Lingxiang, Huarong, Ziyang, Anxiang, and Longshan) that had been directly affected by the Dongting Lake flood in 1998. These eight counties are located in the south of the middle reach of the Yangzi River and form the catchment area of Dongting Lake. Survivors (aged 16 or above) of the disaster from these counties formed the target population. Diagnosis of PTSD was obtained by clinical interviews, and participants who were identified as having PTSD were recorded.

This follow-up study, therefore, considered the group of survivors diagnosed as having PTSD in 2000 in the previous study as the target population. In relation to the degree of destruction caused by the 1998 Dongting Lake flood, the eight affected counties were categorized as mild (Lingxiang and Longshan), moderate (Yueyang, Datonghu and Qianlianghu) and severe (Huarong, Ziyang and Anxiang). One county was randomly selected from each category to form the sampling frame, which consisted of Huarong, Yueyang, and Lingxiang counties. No additional floods had occurred in these three counties since the Dongting Lake flood in 1998. The three counties recorded 584 survivors with a PTSD diagnosis in 2000, and each survivor was considered for follow-up in this study. Excluded from this study were individuals (1) who could not express themselves normally, such as people with an intellectual disability, dementia, and/or a serious illness; (2) who had suffered from other types of intellectual disability or had taken any psychotropic drugs since the PTSD diagnosis in 2000; (3) who had received any psychological intervention since the PTSD diagnosis in 2000; and (4) who had incomplete data following data collection.

\section{Data collection}

Qualified investigators who had either studied in a medical school or had worked for the local Centers for Disease Control and Prevention were appointed to collect data. Uniform training was given to the investigators, using a written investigation manual, before data collection began. Later, investigators conducted face-toface interviews with the participants using a structured questionnaire to collect data regarding demographic characteristics, flood-related stressors, post-flood stressors, social support, and coping style and to ascertain PTSD symptoms. Each investigator received onsite supervision from professional psychologists. A total of 439 survivors with a PTSD diagnosis in 2000 were interviewed in Huarong in November 2013, and a total of 145 
survivors with a PTSD diagnosis in 2000 were interviewed in Yueyang and Lingxiang in September 2014.

\section{Measures \\ Demographic variables}

Gender, age, ethnicity, marital status, and education level were included in the analyses.

\section{Flood-related stressors}

Following the protocol of most studies on natural disasters [16, 17], participants were asked the following questions to examine the intensity of the flood: Have you lost at least one family member? Have you or your family members been physically injured? Have you or your family lost most of your property? Have you or your family lost your livelihood? Have your homes been destroyed? These five questions were treated as dichotomous variables answered with either "Yes" or "No".

\section{Post-flood stressors}

Post-flood stressors, categorized as positive or negative in this study, were used to identify the stress situation in participants from the first investigation in the year 2000 to the present. Participants who suffered from post-flood stressors (e.g., traffic accidents, cancers, loss of a relative, etc.) and who reported feeling terrified (e.g., re-experiencing, avoidance and hyperarousal) were classified as positive for post-flood stressors.

\section{Social support}

The Chinese version of the Social Support Rating Scale (SSRS) was used to assess the level of social support in this study. The Chinese version of the SSRS consists of three dimensions, namely, objective support, subjective support and support utilization. Collectively, the three dimensions have 10 items. The total score of these 10 items determined the level of social support of individuals at follow-up. A higher total score indicated better social support. The total score was classified as low (12-44), medium (45-54) or high (>55) according to the established guidelines. The Chinese version of SSRS has shown good reliability and validity [18].

\section{Coping style}

The Simplified Coping Style Questionnaire (SCSQ), which consists of 2 subscales and 20 items for both subscales, was used to assess coping style in this study. The first subscale, positive coping, has 12 items referring to behaviours that actively buffer the stressful situation, such as "trying to find effective resolutions when faced with a stressful situation." The second subscale, negative coping, has eight items referring to negative behaviours, such as "using intoxicating substances to get relief when faced with a stressful situation." Each item is scored on a 4-point Likert scale, ranging from never ( $=0$ points) to often ( $=3$ points). A subscale score was calculated by averaging the scores of items for the subscale. A higher subscale score indicated more frequent use of the coping style in that subscale. Participants were classified as having positive coping if the positive coping style subscale score was higher than that of the negative coping style subscale. Otherwise, participants were classified as having negative coping. The SCSQ has demonstrated good reliability and validity with a test-retest reliability of 0.89 [19].

\section{PTSD}

PTSD was identified by the PTSD Checklist-Civilian version (PCL-C), which was also used in the first investigation. The PCL-C was developed from the Fourth Edition of the Diagnostic and Statistical Manual of Mental Disorders (DSM-IV) and is a commonly used self-report questionnaire for identifying PTSD. According to some studies, the PCL-C has high internal consistency $(\alpha=0.94)$ [20], with relatively high levels of sensitivity (94-97\%) and specificity (86-99\%) [21]. Moreover, research has shown that the Chinese version of the PCL-C has sound validity and reliability [22]. The PCL-C consists of 17 items that are split into three domains, namely, re-experiencing, avoidance and hyperarousal. Among the 17 items, all items referring to re-experiencing, half of the items referring to avoidance, and half of the items referring to hyperarousal contained event-specific wording (e.g., "... as a result of the Dongting Lake flood in 1998"). The scale of each of the 17 items ranges from 1 (not at all) to 5 (extremely). In this study, a score of 44 was used as a cutoff to identify PTSD at follow-up. The diagnostic efficiency of these criteria was 0.94 [21]. Participants were classified into two groups. The first group was the group that fulfilled the criteria for PTSD diagnosis during the follow-up period, while the second group was the group that met the diagnostic criteria for PTSD in the 2000 survey, but did not meet the diagnostic criteria for PTSD at the follow-up.

\section{Data analyses}

Descriptive statistics were computed for the demographic variables, flood-related stressors, post-flood stressors, social support, and coping style. Univariable logistic regression analyses were used to identify the predictive factors of recovery from PTSD by consecutively exploring the roles of the preceding independent variables on recovery from PTSD. All of the statistically significant independent variables in the univariable logistic regression analyses were then used to perform multivariable logistic regression analyses to identify the independent predictive role of each variable on recovery from 
PTSD [23, 24]. The $95 \%$ confidence intervals $(95 \% \mathrm{CI})$ were provided for each odds ratio (OR). All tests were 2tailed, and the significance level was set at 0.05 . All analyses were performed using SPSS Version 19.0 (IBM Corp, Armonk, NY).

\section{Results}

\section{Sample description}

A total of 584 survivors diagnosed with PTSD following the Dongting Lake flood in 1998 were identified. Of these potential candidates, 39 died of diseases or accidents, 104 migrated to other places, and 230 went to other cities to work. Thus, 211 survivors were contacted for interview representing an availability rate of $36.1 \%$ (211/584) at follow-up. Of the 211 survivors contacted for interviews, 205 completed the questionnaires (Fig. 1). A total of 201 valid questionnaires were included in this study after excluding 4 incomplete questionnaires. A response rate of $98.0 \%(201 / 205)$ was therefore achieved. Compared with those excluded due to non-response or incomplete data, those included in this study were much older (mean age on September 2014: 49 vs. 55 years, $P<0.05)$, but they had similar trauma exposure.

Descriptive data on demographics, flood-related stressors and post-flood stressors are presented in Table 1. Nearly half of the subjects were female. The mean (standard deviation) age of participants was 55 (12.02) years. Among the 201 participants, most were married, and all were of Han Ethnicity. Almost half had not received any education or had only attended primary school. In addition, nearly half of the participants had experienced loss of property or livelihood, and more than one third had been injured. Among all respondents, 13 had lost relatives in the flood. Post-flood trauma exposure was relatively low, with $78 \%$ reporting no postflood stressors.

\section{Univariable analyses}

Based on the PCL-C cut-off score of 44, the prevalence rate of PTSD at follow-up was $19.4 \%(39 / 201)$. The results of univariable analyses indicated that males $(\mathrm{OR}=$ $0.49,95 \% \mathrm{CI}=0.24-0.99$ ) were more likely to recover from PTSD in 2000 compared with females. Additionaly, participants with more serious exposure to flood trauma, such as loss of relatives $(\mathrm{OR}=11.85,95 \% \mathrm{CI}=$ $3.43-40.98)$, bodily injury ( $\mathrm{OR}=3.32,95 \% \mathrm{CI}=1.61$ 6.82), loss of property $(\mathrm{OR}=3.35,95 \% \mathrm{CI}=1.56-7.18)$, loss of livelihood $(\mathrm{OR}=2.07,95 \% \mathrm{CI}=1.01-4.27)$, or damage to home $(\mathrm{OR}=2.36,95 \% \mathrm{CI}=1.16-4.80)$, were less likely to recover from their 2000 PTSD diagnosis. The univariable analyses also showed that individuals with low social support $(\mathrm{OR}=8.57,95 \% \mathrm{CI}=1.92$ 38.36) or a negative coping style $(\mathrm{OR}=6.08,95 \% \mathrm{CI}=$ 2.87-12.84) were less likely to recover from their 2000 PTSD diagnosis (Table 2).

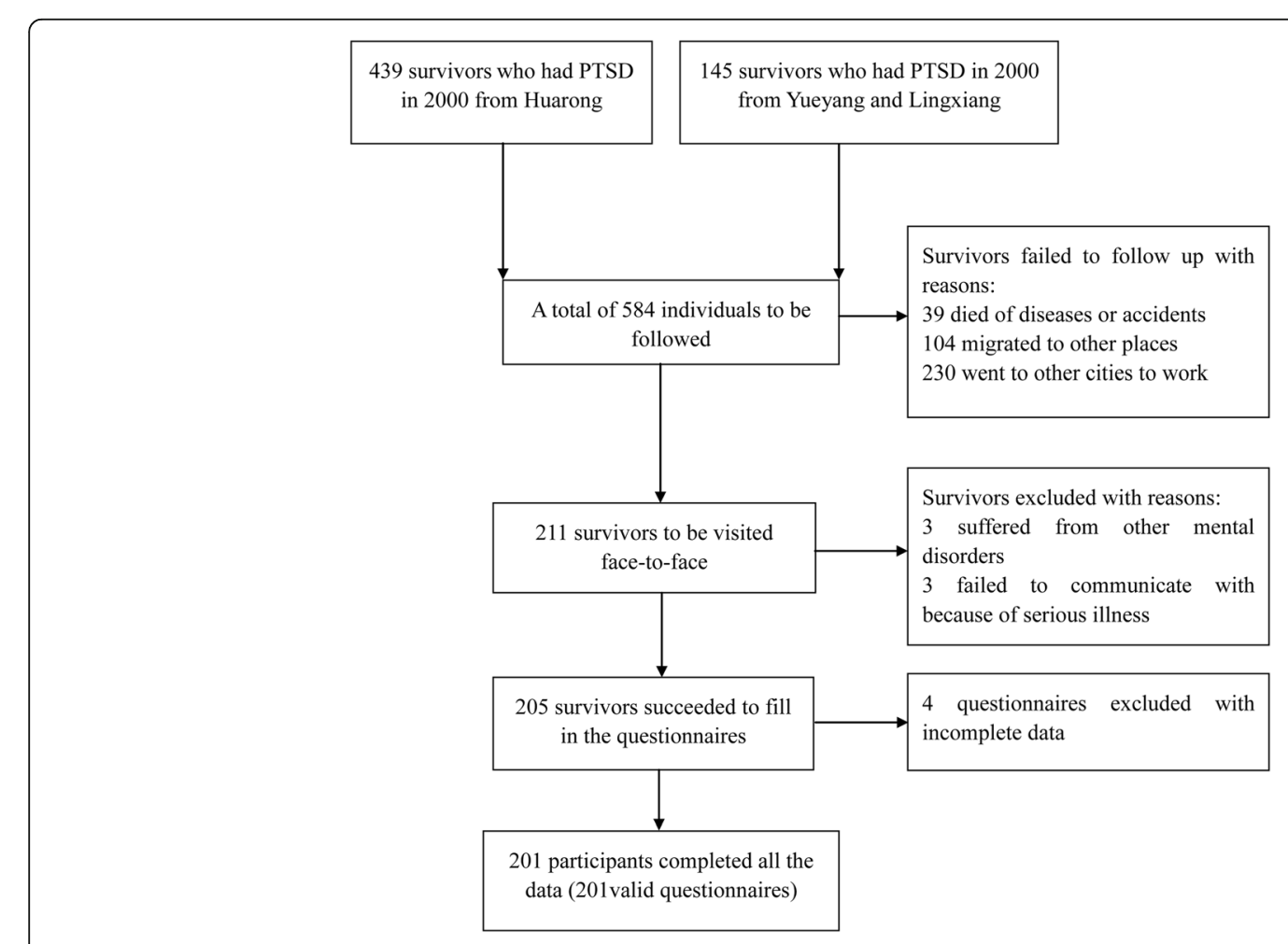

Fig. 1 Flow chart of the participants included in this follow-up study. Presentation of how participants were enrolled in this study 
Table 1 Characteristics of the participants $(n=201)$

\begin{tabular}{|c|c|c|c|}
\hline Variable & & Number & Percent (\%) \\
\hline \multicolumn{4}{|l|}{ Gender } \\
\hline & Female & 90 & 44.8 \\
\hline & Male & 111 & 55.2 \\
\hline Ethnicity & Han & 201 & 100.0 \\
\hline \multicolumn{4}{|c|}{ Marital status } \\
\hline & Married & 182 & 90.5 \\
\hline & Unmarried & 19 & 9.5 \\
\hline \multicolumn{4}{|l|}{ Age } \\
\hline & $30-60$ & 142 & 70.6 \\
\hline & $61-88$ & 59 & 29.4 \\
\hline \multicolumn{4}{|c|}{ Education level } \\
\hline & $\leq$ Primary school & 106 & 52.7 \\
\hline & >Primary school & 95 & 47.3 \\
\hline \multicolumn{4}{|c|}{ Loss of relative } \\
\hline & No & 188 & 93.5 \\
\hline & Yes & 13 & 6.5 \\
\hline \multicolumn{4}{|c|}{ Bodily injury } \\
\hline & No & 129 & 64.2 \\
\hline & Yes & 72 & 35.8 \\
\hline \multicolumn{4}{|c|}{ Loss of property } \\
\hline & No & 103 & 51.2 \\
\hline & Yes & 98 & 48.8 \\
\hline \multicolumn{4}{|c|}{ Loss of livelihood } \\
\hline & No & 101 & 50.2 \\
\hline & yes & 100 & 49.8 \\
\hline \multicolumn{4}{|c|}{ Damage to home } \\
\hline & No & 131 & 65.2 \\
\hline & Yes & 70 & 34.9 \\
\hline \multicolumn{4}{|c|}{ Post-flood stressors } \\
\hline & Negative & 156 & 77.6 \\
\hline & Positive & 45 & 22.4 \\
\hline \multicolumn{4}{|c|}{ Social support } \\
\hline & Low & 79 & 39.3 \\
\hline & Medium & 80 & 39.8 \\
\hline & High & 42 & 20.9 \\
\hline \multicolumn{4}{|c|}{ Coping style } \\
\hline & Negative & 54 & 26.9 \\
\hline & Positive & 147 & 73.1 \\
\hline
\end{tabular}

\section{Multivariable analyses}

The results of multivariable logistic regression analyses are shown in Table 3. All variables that were statistically significant $(P \leq 0.05)$ in the univariable analyses were included in the multivariable model to identify the independent role of each predictor variable after adjustment for confounding. After multivariable analysis, gender, damage to home, loss of property, and loss of livelihood were no longer significantly associated with recovery from the 2000 PTSD diagnosis. The likelihood of PTSD at follow-up was higher for those who had lost relatives $(\mathrm{OR}=12.37,95 \% \mathrm{CI}=2.46-62.16)$, suffered from bodily injury $(\mathrm{OR}=5.01,95 \% \mathrm{CI}=1.92-13.08)$, had a lower level of social support $(\mathrm{OR}=5.47,95 \% \mathrm{CI}=1.07-27.80)$, or had a negative coping style $(\mathrm{OR}=4.92,95 \% \mathrm{CI}=$ 1.89-12.81) than the respective reference groups.

\section{Discussion}

The findings of this study, conducted over 15 years after the Dongting Lake flood in 1998, underscored the longterm impact of PTSD on survivors who were diagnosed with PTSD in 2000. It was found that the prevalence rate of PTSD among these survivors at the 13-14 year follow-up was $19.4 \%$. This prevalence rate emphasizes the importance of early identification of risk for longterm PTSD, which has been previously suggested [2527]. Few studies have investigated PTSD in the long term or beyond 15 years [28, 29]. Among these studies, one showed that $7 \%$ of Buffalo Creek flood survivors had a PTSD diagnosis at the 17-year follow-up [28]. In another study, $29 \%$ of Aberfan disaster survivors met PTSD diagnostic criteria at the 33-year follow-up [29]. Additional research, with shorter longitudinal follow-up times, has found, for example, PTSD prevalence rates of $53 \%$ among $9 / 11$ police responders at the 5-year followup and PTSD prevalence rates of $34.3 \%$ among SARS patients in 2000 at the 4-year follow-up $[5,6]$. It is wellknown that the type of traumatic event and the intensity of disasters may influence PTSD prevalence rates among survivors [15]. Moreover, follow-up time may also affect the PTSD prevalence rate. Longer follow-up time may provide survivors with sufficient time to recover from the trauma and, therefore, could result in a lower PTSD prevalence rate at follow-up.

Loss of relatives and physical injury inflict both physical and psychological pain in flood survivors. In this study, flood survivors who developed PTSD after the flood and had experienced loss of relatives or physical injury were less likely to recover from PTSD compared with their PTSD counterparts who did not experience loss of relatives or physical injury. In addition to this finding, a previous study showed that loss of relatives and physical injury were risk factors for the onset of PTSD after traumatic events [30]. Therefore, traumarelated stressors may not only be related to the onset of PTSD but may also be associated with PTSD recovery. Among the Chinese, for example, whether a family is cohesive plays an important role in one's mental health, and kinship is the centre of the social network. Therefore, experiencing loss of relatives, especially a spouse or 
Table 2 Univariable logistic regression analyses of the effects of demographics, trauma exposure, social support, and coping style on the odds of PTSD at follow-up

\begin{tabular}{|c|c|c|c|c|}
\hline \multirow[b]{2}{*}{ Variable } & \multicolumn{4}{|l|}{ PTSD at follow-up } \\
\hline & & Number (\%) & OR (95 \% Cl) & $P$ \\
\hline Overall & & $39(19.4)$ & & \\
\hline \multirow[t]{2}{*}{ Gender } & Female & $23(25.6)$ & 1 & \\
\hline & Male & $16(14.4)$ & $0.49(0.24-0.99)$ & 0.050 \\
\hline \multirow[t]{2}{*}{ Marital status } & Married & $34(18.7)$ & 1 & \\
\hline & Unmarried & $5(26.3)$ & $0.64(0.22-1.91)$ & 0.426 \\
\hline \multirow[t]{2}{*}{ Age } & $21-60$ & $29(20.4)$ & 1 & \\
\hline & $61-88$ & $10(16.9)$ & $0.79(0.36-1.76)$ & 0.571 \\
\hline \multirow[t]{2}{*}{ Educational level } & $\leq$ Primary school & $24(22.6)$ & 1 & \\
\hline & >Primary school & 15 (15.8) & $0.64(0.31-1.31)$ & 0.222 \\
\hline \multirow[t]{2}{*}{ Loss of relative } & No & $30(16.0)$ & 1 & \\
\hline & Yes & $9(69.2)$ & $11.85(3.43-40.98)$ & 0.000 \\
\hline \multirow[t]{2}{*}{ Bodily injury } & No & $16(12.4)$ & 1 & \\
\hline & Yes & $23(31.9)$ & $3.32(1.61-6.82)$ & 0.001 \\
\hline \multirow[t]{2}{*}{ Loss of property } & No & $11(10.7)$ & 1 & \\
\hline & Yes & $28(28.6)$ & $3.35(1.56-7.18)$ & 0.002 \\
\hline \multirow[t]{2}{*}{ Loss of livelihood } & No & $14(13.9)$ & 1 & \\
\hline & Yes & $25(25.0)$ & $2.07(1.01-4.27)$ & 0.049 \\
\hline \multirow[t]{2}{*}{ Damage to home } & No & $19(14.5)$ & 1 & \\
\hline & Yes & $20(28.6)$ & $2.36(1.16-4.80)$ & 0.018 \\
\hline \multirow[t]{2}{*}{ Post-flood stressors } & Negative & $28(17.9)$ & 1 & \\
\hline & Positive & $11(24.4)$ & $1.48(0.67-3.27)$ & 0.334 \\
\hline \multirow[t]{3}{*}{ Social support } & High & $2(4.8)$ & 1 & \\
\hline & Medium & $24(30.0)$ & $3.94(0.85-18.37)$ & 0.081 \\
\hline & Low & $13(16.5)$ & $8.57(1.92-38.36)$ & 0.005 \\
\hline \multirow[t]{2}{*}{ Coping style } & Positive & $16(10.9)$ & 1 & \\
\hline & Negative & $23(42.6)$ & $6.08(2.87-12.84)$ & 0.000 \\
\hline
\end{tabular}

parents, may be particularly stressful for Chinese citizens. Additionally, the quality of life of individuals who have experienced bodily injury from the flood may be seriously affected by pain or disability brought about by the disaster. Therefore, it may be more difficult for them to recover from PTSD.

Social support refers to the quality and function of social relationships, and may have an effect on the way one copes with stress [31]. In this study, a high level of

Table 3 Multivariable logistic regression analyses of the factors significantly associated with PTSD at follow-up

\begin{tabular}{lllrll}
\hline Variable & B & SE & \multicolumn{1}{c}{ Wald } & OR $(95 \% \mathrm{Cl})$ & $P$ \\
\hline Loss of relative & 2.515 & 0.824 & 9.327 & $12.37(2.46-62.16)$ & 0.002 \\
Bodily injury & 1.612 & 0.489 & 10.845 & $5.01(1.92-13.08)$ & 0.001 \\
Low social support & 1.698 & 0.830 & 4.188 & $5.47(1.07-27.80)$ & 0.041 \\
Negative coping & 1.593 & 0.488 & 10.651 & $4.92(1.89-12.81)$ & 0.001 \\
\hline
\end{tabular}

social support was found to be a predictor of PTSD recovery in flood survivors. This is in agreement with a previous study that found that social resources can provide a buffer against psychological distress following potentially traumatic events [32]. Moreover, social support also correlates with the onset of PTSD [33]. Our study found that social support was correlated with PTSD recovery. Therefore, it is important to provide more social resources to individuals who have experienced trauma, as these resources may have long-term impacts in alleviating the psychological effects caused by traumatic events.

Many previous studies have demonstrated that coping style is related to psychological outcome among individuals who have experienced trauma [34, 35]. Furthermore, Bonanno and his team found that deficits in coping flexibility were indicative of pathology in bereaved individuals [36]. Similar to their results, the 
present study found that coping style was significantly related to recovery from PTSD in flood survivors, and this is in support of the view that the ability to remain optimistic could be an effective way to cope with adverse events [37]. When faced with a trauma, individuals with a negative coping style were more likely to feel depressed, even hopeless [38, 39], which could negatively impact their recovery from mental illnesses.

With reference to previous studies, there have been contradictory results about the vulnerability of developing PTSD after traumatic events based on gender. Some studies have reported that females have a higher risk for PTSD symptoms [40-42], while other research has shown that males are more likely to develop PTSD symptoms after traumatic events [43]. The results of the present study showed that females were less likely to recover from prior PTSD in univariable analysis, but being female proved not to be an independent predictor of recovery from prior PTSD in the multivariabe analysis. Moreover, the effects of education level and age on the incidence of PTSD are controversial $[40,44,45]$, and the results of this study indicated that neither variable was significantly related to PTSD recovery in flood survivors.

The role of stressful life events on the course of PTSD has been previously investigated [46]. For example, at follow-up 7-8 years after September 11, 2001 with the police officers who experienced the events, James found that $41.0 \%$ had at least 2 life-threatening stressors since the terror attack [5]. In our study, $22.4 \%$ of the participants reported post-flood stressors at a longer follow-up period than that in James' study. This is mainly because the post-flood stressors indicated in this study included an assessment of the number of stressful life events and a rating of how terrified the person felt by each event. Thus, the rate of individuals who reported having both stressful life events (e.g., traffic accidents, cancers, loss of a relative, etc.) and feeling terrified (e.g., reexperiencing, avoidance and hyperarousal) may be decreased. However, this study found that post-flood stressors were not significantly associated with recovery from PTSD, although previous studies have indicated that post-disaster stressors or stressful life events were related to the psychological outcome of individuals following traumatic events $[5,46]$.

Despite having no significant correlation with PTSD recovery, it is worth noting that post-flood stressors play an important role in the course of PTSD. The reason for the lack of a significant relationship between them could be attributed to the fact that the post-flood stressors identified in this study were measured after a 13-14 year gap since the year 2000. This reasoning is supported by Perez, who found that the number of trauma exposures were a predictor of a worse course of PTSD, but only during some intervals in the 15-year follow-up period [47]. Therefore, it is possible that post-flood stressors and recovery from PTSD might be significantly correlated at the time when the participants were exposed to the post-flood stressors, but not when the follow-up study was conducted.

This study had some limitations that should be acknowledged. Firstly, the impact of income could not be analyzed because most of the participants did not want to provide information about their income. Secondly, fluctuations of PTSD symptoms over time were not assessed. Thirdly, participants who enrolled in this study were likely to have a chronic course since they were diagnosed with PTSD in 2000, almost 2 years after the Dongting Lake flood. Thus, the prevalence of PTSD at the 13-14 year follow-up may be overestimated. Finally, all participants of this study were Chinese of Han Ethnicity. Hence, the results may not be applicable to flood survivors in other populations.

\section{Conclusions}

This follow-up study explored predictors of recovery from PTSD in flood survivors who experienced the 1998 Dongting Lake flood and were diagnosed with PTSD in 2000. The prevalence rate of PTSD among this group at the 13-14 year follow-up since the diagnosis of PTSD in 2000 was $19.4 \%$. Traumatic events such as floods may negatively affect survivors for a long period of time. Individuals who lost relatives due to the flood, suffered from bodily injury, had a low level of social support, or had a negative coping style after the flood were less likely to recover from PTSD. Therefore, with little or no psychological intervention following trauma, approximately one in five individuals diagnosed with PTSD at 2 years post-event will continue to experience severe PTSD symptoms, even 15 years later. More research is needed to design and evaluate early interventions following disasters, particularly for those with increased vulnerability.

\section{Abbreviations \\ $95 \%$ Cl: $95 \%$ confidence interval; DSM-5: Fifth edition of the diagnostic and statistical manual of mental disorders; DSM-IV: Fourth edition of the diagnostic and statistical manual of mental disorders; OR: Odds ratio; PCL-C: PTSD Checklist-Civilian version; PTSD: Post-traumatic stress disorder; SARS: Severe acute respiratory syndrome; SCSQ: Simplified coping style questionnaire; SSRS: Social support rating scale}

\section{Acknowledgements \\ The authors are grateful to all participants, investigators, officials and community workers of the local government.}

\section{Funding}

This research was funded by the Specialized Research Fund for the Doctoral Program of Higher Education (20130162110054) and the Fundamental Research Funds for the postgraduates of Central South University (2015zzts282). 


\section{Availability of data and materials}

Available upon request to the corresponding author Aizhong Liu: lazroy@live.cn

\section{Authors' contributions}

WD, JW, LC and ZL participated in the field survey. WD drafted the manuscript. AL contributed to the study design. AK, JD and HT contributed to the data collection. AK and JD contributed to the analysis and interpretation of the data. JW, AK and JD helped to edit the language. All authors participated in the critical revision of the manuscript drafts and approved the final version.

\section{Competing interests}

The authors declare that they have no competing interests.

\section{Consent for publication}

Not applicable.

\section{Ethics approval and consent to participate}

The investigation was performed in accordance with the latest version of the Declaration of Helsinki. The Ethics Committee of the Institute of Clinical Pharmacology, Central South University of China, approved this investigation and written informed consent was obtained from the participants.

\section{Author details}

'Department of Epidemiology and Health Statistics, Xiangya School of Public Health, Central South University, Hunan, China. ${ }^{2}$ Department of Pediatrics, University of Pittsburgh School of Medicine, Pittsburgh, USA. ${ }^{3}$ Department of Mathematics, Mzuzu University, Mzuzu, Malawi. ${ }^{4}$ Zhuhai Center for Disease Control and Prevention, Guangdong, China. ${ }^{5}$ Hunan Provincial Center for Disease Control and Prevention, Hunan, China.

\section{Received: 25 January 2016 Accepted: 30 October 2016}

\section{Published online: 08 November 2016}

\section{References}

1. Bovin MJ, Marx BP, Weathers FW, Gallagher MW, Rodriguez P, Schnurr PP, et al. Psychometric properties of the PTSD checklist for diagnostic and statistical manual of mental disorders-fifth edition (PCL-5) in veterans. Psychol Assess. 2015. doi:10.1037/pas0000254.

2. Olatunji BO, Cisler JM, Tolin DF. Quality of life in the anxiety disorders: a meta-analytic review. Clin Psychol Rev. 2007;27(5):572-81. doi:10.1016/j.cpr. 2007.01.015.

3. Hidalgo RB, Davidson JR. Posttraumatic stress disorder: epidemiology and health-related considerations. J Clin Psychiatry. 2000;61 Suppl 7:5-13.

4. Perkonigg A, Pfister $H$, Stein MB, Hofler M, Lieb R, Maercker A, et al. Longitudinal course of posttraumatic stress disorder and posttraumatic stress disorder symptoms in a community sample of adolescents and young adults. Am J Psychiatry. 2005;162(7):1320-7. doi:10.1176/appi.ajp. 162.7.1320.

5. Cone JE, Li J, Kornblith E, Gocheva V, Stellman SD, Shaikh A, et al. Chronic probable PTSD in police responders in the world trade center health registry ten to eleven years after 9/11. Am J Ind Med. 2015;58(5):483-93. doi:10.1002/ajim.22446

6. Hong $X$, Currier GW, Zhao $X$, Jiang $Y$, Zhou W, Wei J. Posttraumatic stress disorder in convalescent severe acute respiratory syndrome patients: a 4year follow-up study. Gen Hosp Psychiatry. 2009;31 (6):546-54. doi:10.1016/j. genhosppsych.2009.06.008

7. Celebi Oncu E, Wise AM. The effects of the 1999 Turkish earthquake on young children: analyzing traumatized children's completion of short stories. Child Dev. 2010;81(4):1161-75. doi:10.1111/j.1467-8624.2010.01460.x.

8. Gil S, Weinberg M, Or-Chen K, Harel H. Risk factors for DSM 5 PTSD symptoms in Israeli civilians during the Gaza war. Brain and behavior. 2015;5(4), e00316. doi:10.1002/brb3.316.

9. Liu A, Tan H, Zhou J, Li S, Yang T, Wang J, et al. An epidemiologic study of posttraumatic stress disorder in flood victims in Hunan China. Can J Psychiatry. 2006;51(6):350-4.

10. Breisinger $C$, Ecker $\mathrm{O}$, Thiele R, Wiebelt M. Effects of the 2008 flood on economic performance and food security in Yemen: a simulation analysis. Disasters. 2015. doi:10.1111/disa.12147.

11. Wu J, Xiao J, Li T, Li X, Sun H, Chow EP, et al. A cross-sectional survey on the health status and the health-related quality of life of the elderly after flood disaster in Bazhong city, Sichuan, China. BMC Public Health. 2015;15:163. doi:10.1186/s12889-015-1402-5.

12. Zhang $Q$, Zhang J, Jiang L, Liu X, Tong Z. Flood disaster risk assessment of rural housings-a case study of Kouqian Town in China. Int J Environ Res Public Health. 2014;11(4):3787-802. doi:10.3390/ijerph110403787.

13. Huang $\mathrm{P}$, Tan $\mathrm{H}$, Liu A, Feng $\mathrm{S}$, Chen M. Prediction of posttraumatic stress disorder among adults in flood district. BMC Public Health. 2010;10:207. doi:10.1186/1471-2458-10-207.

14. Tan H, Ping W, Yang T, Li S, Liu A, Zhou J, et al. The synthetic evaluation model for analysis of flooding hazards. Eur J Pub Health. 2007;17(2):206-10. doi:10.1093/eurpub/ckl067.

15. Feng S, Tan H, Benjamin A, Wen S, Liu A, Zhou J, et al. Social support and posttraumatic stress disorder among flood victims in Hunan, China. Ann Epidemiol. 2007;17(10):827-33. doi:10.1016/j.annepidem.2007.04.002.

16. Zhang Z, Shi Z, Wang L, Liu M. Post-traumatic stress disorder, anxiety and depression among the elderly: a survey of the hard-hit areas a year after the Wenchuan earthquake. Stress Health. 2012;28(1):61-8. doi:10.1002/smi.1403.

17. Wang L, Zhang $Y$, Wang W, Shi Z, Shen J, Li M, et al. Symptoms of posttraumatic stress disorder among adult survivors three months after the Sichuan earthquake in China. J Trauma Stress. 2009;22(5):444-50.

18. Xu J, Ou L. Resilience and quality of life among Wenchuan earthquake survivors: the mediating role of social support. Public Health. 2014;128(5): 430-7. doi:10.1016/j.puhe.2014.03.002.

19. Zhang L, Li XX, Hu XZ. Post-traumatic stress disorder risk and brain-derived neurotrophic factor Val66Met. World J Psychiatry. 2016;6(1):1-6. doi:10.1002/ hipo.2259910.5498/wjp.v6.i1.1.

20. Ruggiero KJ, Del Ben K, Scotti JR, Rabalais AE. Psychometric properties of the PTSD Checklist-Civilian Version. J Trauma Stress. 2003;16(5):495-502. doi:10.1023/a:1025714729117.

21. Blanchard EB, Jones-Alexander J, Buckley TC, Forneris CA. Psychometric properties of the PTSD Checklist (PCL). Behav Res Ther. 1996;34(8):669-73.

22. Li H, Wang L, Shi Z, Zhang Y, Wu K, Liu P. Diagnostic utility of the PTSD Checklist in detecting ptsd in Chinese earthquake victims. Psychol Rep. 2010;107(3):733-9. doi:10.2466/03.15.20.pr0.107.6.733-739.

23. Zhang Z, Wang W, Shi Z, Wang L, Zhang J. Mental health problems among the survivors in the hard-hit areas of the Yushu earthquake. PLoS One. 2012;7(10):e46449. doi:10.1371/journal.pone.0046449.

24. Chen $G$, Shen H, Chen G. A cross-sectional study on posttraumatic stress disorder among elderly Qiang citizens 3 years after the Wenchuan earthquake in China. Can J Psychiatry. 2012:57(9):547-53.

25. Karstoft KI, Statnikov A, Andersen SB, Madsen T, Galatzer-Levy IR. Early identification of posttraumatic stress following military deployment: application of machine learning methods to a prospective study of Danish soldiers. J Affect Disord. 2015;184:170-5. doi:10.1016/j.jad.2015.05.057.

26. Bryant RA, Nickerson A, Creamer M, O'Donnell M, Forbes D, Galatzer-Levy I, et al. Trajectory of post-traumatic stress following traumatic injury: 6-year follow-up. Br J Psychiatry. 2015;206(5):417-23. doi:10.1192/bjp.bp.114.145516.

27. Dekel S, Ein-Dor T, Gordon KM, Rosen JB, Bonanno GA. Cortisol and PTSD symptoms among male and female high-exposure 9/11 survivors. J Trauma Stress. 2013;26(5):621-5. doi:10.1002/jts.21839.

28. Green BL, Grace MC, Vary MG, Kramer TL, Gleser GC, Leonard AC. Children of disaster in the second decade: a 17-year follow-up of Buffalo Creek survivors. J Am Acad Child Adolesc Psychiatry. 1994;33(1):71-9. doi:10.1097/ 00004583-199401000-00011.

29. Morgan L, Scourfield J, Williams D, Jasper A, Lewis G. The Aberfan disaster: 33-year follow-up of survivors. Br J Psychiatry. 2003;182:532-6.

30. Tiihonen Moller A, Backstrom T, Sondergaard HP, Helstrom L. Identifying risk factors for PTSD in women seeking medical help after rape. PLoS One. 2014;9(10), e111136. doi:10.1371/journal.pone.0111136.

31. Dai W, Chen L, Tan H, Wang J, Lai Z, Kaminga AC, et al. Association between social support and recovery from post-traumatic stress disorder after flood: a 13-14 year follow-up study in Hunan, China. BMC Public Health. 2016;16:194. doi:10.1186/s12889-016-2871-x.

32. Hall BJ, Bonanno GA, Bolton PA, Bass JK. A longitudinal investigation of changes to social resources associated with psychological distress among Kurdish torture survivors living in Northern Iraq. J Trauma Stress. 2014;27(4):446-53. doi:10.1002/jts.21930.

33. Verreault N, Da Costa D, Marchand A, Ireland K, Banack H, Dritsa M, et al. PTSD following childbirth: a prospective study of incidence and risk factors in Canadian women. J Psychosom Res. 2012;73(4):257-63. doi:10.1016/j. jpsychores.2012.07.010. 
34. McNeill SA, Galovski TE. Coping styles among individuals with severe mental illness and comorbid PTSD. Community Ment Health J. 2015;51(6):663-73. doi:10.1007/s10597-015-9887-z.

35. Loo GT, DiMaggio CJ, Gershon RR, Canton DB, Morse SS, Galea S. Coping behavior and risk of post-traumatic stress disorder among federal disaster responders. Disaster Med Public Health Prep. 2016;10(1):108-17. doi:10.1017/ dmp.2015.141.

36. Burton $\mathrm{CL}$, Yan OH, Pat-Horenczyk R, Chan IS, Ho S, Bonanno GA. Coping flexibility and complicated grief: a comparison of American and Chinese samples. Depress Anxiety. 2012;29(1):16-22. doi:10.1002/da.20888.

37. Bonanno GA, Keltner D, Holen A, Horowitz MJ. When avoiding unpleasant emotions might not be such a bad thing: verbal-autonomic response dissociation and midlife conjugal bereavement. J Pers Soc Psychol. 1995;69(5):975-89.

38. Karstoft Kl, Armour C, Elklit A, Solomon Z. The role of locus of control and coping style in predicting longitudinal PTSD-trajectories after combat exposure. J Anxiety Disord. 2015;32:89-94. doi:10.1016/j.janxdis.2015.03.007.

39. Harris LS, Block SD, Ogle CM, Goodman GS, Augusti EM, Larson RP et al. Coping style and memory specificity in adolescents and adults with histories of child sexual abuse. Memory (Hove, England). 2015:1-13. doi:10.1080/09658211.2015.1068812.

40. Zaffina S, Camisa V, Monducci E, Vinci MR, Vicari S, Bergamaschi A. PTSD prevalence and associated risk factors after a fire disaster that broke out in a paediatric hospital: a cross-sectional study. La Medicina del lavoro. 2014;105(3):163-73.

41. Polusny MA, Kumpula MJ, Meis LA, Erbes CR, Arbisi PA, Murdoch M, et al. Gender differences in the effects of deployment-related stressors and pre-deployment risk factors on the development of PTSD symptoms in National Guard Soldiers deployed to Iraq and Afghanistan. J Psychiatr Res. 2014;49:1-9. doi:10.1016/j.jpsychires.2013.09.016.

42. Spinhoven P, Penninx BW, van Hemert AM, de Rooij M, Elzinga BM. Comorbidity of PTSD in anxiety and depressive disorders: prevalence and shared risk factors. Child Abuse Negl. 2014;38(8):1320-30. doi:10.1016/j. chiabu.2014.01.017.

43. Fu Y, Chen Y, Wang J, Tang X, He J, Jiao M, et al. Analysis of prevalence of PTSD and its influencing factors among college students after the Wenchuan earthquake. Child Adolesc Psychiatry Ment Health. 2013;7(1):1. doi:10.1186/1753-2000-7-1.

44. Kolltveit $\mathrm{S}$, Lange II N, Thabet AA, Dyregrov A, Pallesen S, Johnsen TB, et al Risk factors for PTSD, anxiety, and depression among adolescents in Gaza. J Trauma Stress. 2012;25(2):164-70. doi:10.1002/jts.21680.

45. Mak IW, Chu CM, Pan PC, Yiu MG, Ho SC, Chan VL. Risk factors for chronic post-traumatic stress disorder (PTSD) in SARS survivors. Gen Hosp Psychiatry. 2010;32(6):590-8. doi:10.1016/j.genhosppsych.2010.07.007.

46. van der Velden PG, Bosmans MW, Bogaerts S, van Veldhoven MJ. Social organizational stressors and post-disaster mental health disturbances: a longitudinal study. Psychiatry Res. 2014;219(1):177-82. doi:10.1016/j.psychres. 2014.05.032.

47. Perez Benitez Cl, Zlotnick C, Dyck I, Stout R, Angert E, Weisberg R, et al. Predictors of the long-term course of comorbid PTSD: a naturalistic prospective study. Int J Psychiatry Clin Pract. 2013;17(3):232-7. doi:10.3109/13651501.2012.667113.

\section{Submit your next manuscript to BioMed Central and we will help you at every step:}

- We accept pre-submission inquiries

- Our selector tool helps you to find the most relevant journal

- We provide round the clock customer support

- Convenient online submission

- Thorough peer review

- Inclusion in PubMed and all major indexing services

- Maximum visibility for your research

Submit your manuscript at www.biomedcentral.com/submit 